Review

\title{
Synaptic Plasticity and Learning Processes: A Neuroeducation Perspective
}

Debora Di Jorio *

Centro Psicopedagogico Formazione Studi e Ricerche OIDA - Naples, Italy; E-Mail: deboradijorio@centrooida.it

* Correspondence: Debora Di Jorio; E-Mail: deboradijorio@centrooida.it

Academic Editor: Ping K. Yip

Special Issue: Neuroprotection, Neuroregeneration and Neuroplasticity

OBM Neurobiology

2020, volume 4, issue 2

doi:10.21926/obm.neurobiol.2002063
Received: April 14, 2020

Accepted: June 12, 2020

Published: June 22, 2020

\begin{abstract}
The story of each individual is essentially the story of their learning processes and relationships from the moment they were born. Indeed, the story of learning processes is merely a constant stratification of experiences based on biological and neurofunctional features that are influenced by genetic and cultural factors and subject to environmental stimuli constantly reshaping their behaviour.

Neuroscientific studies conducted over the past decades have highlighted a unique feature of the human nervous system, called neural plasticity which enables the development of beneficial or detrimental requirements for human health.

From their birth, infants are inundated with plethora of stimuli, and their brains have to gradually connect these stimuli to something or someone, or assign them a meaning, so that the child will be able to interact with them in a consistent way at a later stage.

All they are endowed with by nature makes up the biological features they need to relate to the surrounding world. Their sensory system enables infants to interpret environmental data and respond through motor sequences that get increasingly organized, allowing them to act appropriately in space through visual orientation.
\end{abstract}

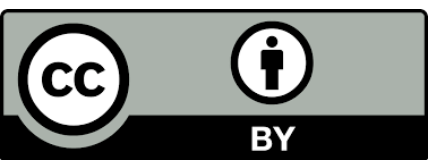

(C) 2020 by the author. This is an open access article distributed under the conditions of the Creative Commons by Attribution License, which permits unrestricted use, distribution, and reproduction in any medium or format, provided the original work is correctly cited. 
The presence of caregivers is a necessary condition for their survival, and also for the transmission of any type of explicit learning. Man cubs soon learn that each of their calls elicits a response aimed at satisfying all their needs. With time, this kind of experience will help them to trust the surrounding environment, and will significantly contribute to the development of their self-esteem.

Therefore, when educational activity is imbued with this awareness, it becomes a neuroeducational activity, aimed at enhancing human cognitive skills through generalized (perception, motor skills, language) and educational (reading, writing, and computational skills) learning processes. These stimulate motor and manipulative activity and promote relationships, experiences, and social sharing. All of this by means of a slow and intense path of targeted stimulations that affect the lower levels of brain maturation.

\section{Keywords}

Plasticity; learning; neuroeducation; development; evolution; motor skills

The story of each individual is essentially the story of their learning processes and relationships from the moment they were born. Indeed, the story of learning processes is merely a constant stratification of experiences based on biological and neurofunctional features that are influenced by genetic and cultural factors and subject to environmental stimuli constantly reshaping their behavior.

Neuroscientific studies conducted over the past decades have highlighted a unique feature of the human nervous system, called neural plasticity which enables the development of beneficial or detrimental requirements for human health.

From their birth, infants are inundated with a plethora of stimuli, and their brains have to gradually connect these stimuli to something or someone, or assign them a meaning, so that the child will be able to interact with them in a consistent way at a later stage.

All they are endowed with by nature makes up the biological features they need to relate to the surrounding world. Their sensory system enables infants to interpret environmental data and respond through motor sequences that get increasingly organized, allowing them to act appropriately in space through visual orientation.

The presence of caregivers is a necessary condition for their survival and also for the transmission of any type of explicit learning. Man cubs soon learn that each of their calls elicits a response aimed at satisfying all their needs. With time, this kind of experience will help them to trust the surrounding environment, and will significantly contribute to the development of their self-esteem.

Considering this, educational dynamics have an important role to play in the relational field. Since such dynamics are a prerogative of educational knowledge; they must take into account the specific biological and environmental conditions that promote a healthy development using targeted stimulations of different brain areas.

Neurologist Oliver Sacks introduced the principles of a new educational perspective that are the basis of neuroeducation. In his novel "An Anthropologist on Mars" he argued that for the pedagogue it is particularly important to know the uniqueness of the path created by the nervous 
system of a child with a defect, in order to achieve a qualitatively different type of adaptation. He further emphasized that an educational or rehabilitation project could only be effective if the uniqueness of each human being is taken into account.

Hence, pedagogists should deepen their knowledge of brain development to identify a personal, non-standard way of learning for each individual [1].

The network of synaptic connections developed during an individual's life, regardless of the starting conditions, is influenced by the different information, contacts, and relationships that one experiences daily. It is the result of reasoning, actions, feelings, perception of the outer world constantly mingled with the individual's past inner experiences, the way they are interpreted in the present, and incessantly dialoguing with stimuli from the outer environment, and creating exclusive forms of adaptation. Ansermet and Magistretti concluded that these did not undermine the deterministic aspect of learning, based on a biological condition that plasticity itself produces using long-lasting traces left by experience.

We need to sift through the barrages of data that inundate us and deal with our inner psychic reality or a phenomenological perspective called narration, but also with an evolutionary history that individuals invoke every time they need to contextualize their actions/reactions.

According to Kandel, the level of expression of a given gene can be determined by the particularities of experience, which demonstrates the importance of epigenetic factors in the fulfilment of the genetic program [2].

All of the above results in an individual human physiognomy characterized by the integration of old and new elements, genetic makeup, psychic processes, and the real-world, occurring against a deterministic backdrop and are susceptible to change gradually, as we have learned from evolutionary processes.

This will give rise to interpretations of unique environmental data that are incompetent for a response. Each individual's response, at their different ages, is based on their physical, functional and physiological traits, as well as on the emotional charge triggered by these data. This affects their motivation to respond, the type of response and the decision they make, often unconsciously [3].

Beau Lotto, in his neuroscience essay focused on perception, pointed out that the gaps in the information we generally perceive allow our brain to work out a representation of reality that is limited and incomplete, undefined, and remote, therefore subjected to constant changes. Moreover, relational experience, particularly educational action, since it is a resource of the individual growth pathway, must necessarily take them into account.

While all the information we perceive may be meaningless, without a million different simultaneous and interactive ambiguities the brain has nothing to feed its vast interpretation system. Context and the relationships that define it are always changing [....] Your brain takes all the relationships it gathers from context and assigns behavioral meaning to them. This is another way to say the key is action... which bridges past perception to the present [4].

A key role is played by the motor control, whose circuits involve the cortex and several systems located in deep areas of the neurological organization, such as the basal ganglia and the warehouse of emotions, the amygdala.

In the first months of life, infants constantly receive stimuli, mainly visual, and adopt simple motor schemes aimed at guiding their hands in space to reach for objects and persons, at first using palmar prehension and subsequently digital grip. Adults contribute to this experimentation 
phase by handing the infants different objects and naming them, to promote language development, categorization and classification processes, perceptual constancy, and selection of usage functions

During the crawling phase, muscle and binocular vision maturation enables infants to move their bodies in space more freely and to autonomously reach small targets as a result of an imitative learning process.

Motor skills encourage the first interactions, as with the maturation of sensorimotor skills, children are able to recognize others and their intentions. This is also made possible by the mirror neurons, discovered in the early 1990s by a team of researchers led by Giacomo Rizzolatti at the Neuroscience Department of the University of Parma. Mirror neurons activate the premotor and parietal cortex of an individual who executes or observes similar actions made by others and understands the emotional implications of this experience.

Motor, emotional, and motivational circuits are interconnected, and all their actions are aimed at satisfying a need. In support of this claim, Rizzolatti, building on previous insights by Edmund Husserl, recognizes in the use of an object the connection with the human body, as if at that moment the object became an extension of one of its organs. Therefore, our vision of that experience won't be limited to our individual physical connection with what surrounds us, our position in space, and our motor skills, but it will be extended to the body of others that are recognized as being similar to us. From this perspective, every motor experience is also seen as a social experience, a sharing opportunity, as an action carried out on an intersubjective background [5].

Therefore, when educational activity is imbued with this awareness, it becomes a neuroeducational activity, aimed at enhancing human cognitive skills through generalized (perception, motor skills, language) and educational (reading, writing, and computational skills) learning processes. These stimulate motor and manipulative activity and promote relationships, experiences, and social sharing. All of this by means of a slow and intense path of targeted stimulations that affect the lower levels of brain maturation.

Alberto Oliverio wrote that "education has the task to shape the brain", and neuro-education is centered on the neural plasticity feature of the brain that produces neurons and countless connections under the influence of experience [6], whose potential, argues Stanislas Dehaene, is equal to that of genes.

"Given all of this, I would like to emphasize to families with dyslexic children that genetics is not a life sentence. The brain is a plastic organ, which constantly changes and rebuilds itself and for which genes and experience share equal importance. Neuronal migration anomalies, when they are present, affect only very small parts of the cortex. The child's brain contains millions of redundant circuits that can compensate for each other's deficiencies. Each new learning episode modifies our gene expression patterns and alters our neuronal circuits, thus providing the opportunity to overcome dyslexia and other developmental deficits" [7].

Based on this unique feature of the human nervous system, Dehaene formulated the neuronal recycling hypothesis, arguing that neurons intended for specific use could convert to new uses. For example, neurons capable of storing and visually processing the shape of objects recycled into neurons specializing in the decoding of graphic signs, namely letters, creating our natural predisposition to read in the left occipitotemporal area [7]. 
Neuroeducation programs are based on functional exercise, whose focus is the body. The body that moves in the world and changes, that incarnates the resources of the mind, expresses emotions and overcomes Descartes' dualism between the "thinking thing" and the "extended thing", because the body is the direct expression of emotions. Damasio stressed that emotions are never totally disconnected from reasoning, and neither are the feelings, which are mainly expressed through the body.

According to Damasio: "Feelings are neither intangible nor elusive. Contrary to traditional scientific opinion, feelings are just as cognitive as other percepts. They are the result of a most curious physiological arrangement that has turned the brain into the body's captive audience" [8].

Their function is connected to the attainment of homeostasis, of which they are a mental representation, in the evolutionary attempt for man to achieve a balance that ensures the survival of our species [9].

As reported by Damasio, a century earlier, William James had stated: "What kind of an emotion of fear would be left if the feeling neither of quickened heartbeats nor of shallow breathing, neither of trembling lips [...] were present, it is quite impossible for me to think" [8].

Against this background, the involvement of the body in the learning experience becomes quite apparent. The more emotionally poignant and tangible the experience, the longer it will leave traces in the memory and will affect the future responses by paving the way for creative adaptation.

Decision-making processes will also be characterized by this principle. There is not always a high level of awareness in the different learning types, many of them being the legacy of memories built in the early childhood, movement patterns, automatic behaviors in which cortical activity is scarcely involved, motivations to act that have deep, hidden roots, rationally reshaped by the consciousness that does not allow any cracks to its wholeness.

The decision about what should or should not happen is made through a deep unconscious processing [10], of which consciousness is not the origin. It is an external representation and a prompt response that could hardly be expected from conscious control.

The somatic-marker hypothesis formulated by Damasio is what can determine the response to specific stimuli, since the emotional and bodily state function as an alarm bell and influence the perception of a specific course of action [8].

According to Umberto Galimberti, language has always adopted bodily metaphors to describe both pain and joy, to stress the physical nature of any experience [11].

The evolution of learning in a stimulating social and cultural context, not poor and destitute but neither too opulent, facilitates the creation of memories and the ability to anticipate events, using watchfulness and sensorimotor mechanisms that help individuals opt for the best response promptly and stay safe.

Faced with unexpected events, though, consciousness must necessarily be involved, and in this case, the response will be slower, to allow time for the individual to be able to cautiously respond to the new stimulation, before registering it as a new experience and add it to the past ones [12]. Similarly to the rules put in place by basal ganglia during motor control, subcortical circuit mechanisms are not different from those needed to describe cognitive processes, with a succession of programmed, yet modifiable and adaptable sequences, in line with the principle of the human condition and the blind logic of evolution [13]. 
Therefore, neuroeducational knowledge becomes knowledge of the evolution of brain circuits that produce conscious and unconscious learning, decision-making processes, perceptions and interpretations, total involvement of emotions and feelings in the evolutionary history of each individual, and this for the purposes of a context-based, customized educational practice that incorporates human biology, genetics, cultural anthropological heritage and all the possibilities carried by individuals. While education has the task of shaping the brain [14], the latter is characterized by plasticity. Its learning and reshaping tools are the body, the concreteness of touch, and motor action, without which the thought and cognitive activity would be inexorably weakened, regardless of any technological achievement claiming that the human visual system is the only toe hold of mental activity, poorly integrated with the other sensory skills, and representing an abstract and rather distorted reality.

Neural plasticity enables neuroeducation to redesign the possibilities granted to education to reshape the future of human beings.

\section{Author Contributions}

Debora Di Jorio did all the research work of this study.

\section{Competing Interests}

The authors have declared that no competing interests exist.

\section{References}

1. Sacks O. An anthropologist on Mars. NY: Alfred A. Knopf; 1995.

2. Ansermet $F$, Magistretti P. A chacun son cerveau, plasticité neuronale et inconscient. Paris: Éditions Odile Jacob; 2016

3. Ansermet $F$, Magistretti P. Les énigmes du plaisir. Paris: Éditions Odile Jacob; 2012

4. Lotto B. Deviate: The science of seeing differently. Paris: Hachette Livre; 2017

5. Rizzolatti G, Sinigaglia C. So quel che fai. Milan: Raffaello Cortina Editore; 2006.

6. Oliverio A. Il cervello che impara. Florence: Giunti Editore;2017

7. Dehaene S. Les neurones de la lecture. Milan: Raffaello Cortina Editore; 2007.

8. Damasio A. Descartes' error. Milan: Adelphi; 2012.

9. Damasio A. The strange order of things. Milan: Adelphi; 2018.

10. Maldonato M. Quando decidiamo: Siamo attori consapevoli o macchine biologiche? Florence: Giunti Editore; 2015

11. Soresi E. Il cervello anarchico. Turin: UTET; 2013.

12. Dehaene S. Consciousness and the brain. Milan: Raffaello Cortina Editore; 2018.

13. Lieberman P. The unpredictable species: What makes humans unique. Roma: Carocci Editore; 2016.

14. Oliverio A. La vita nascosta del cervello. Florence: Giunti Editore; 2013. 


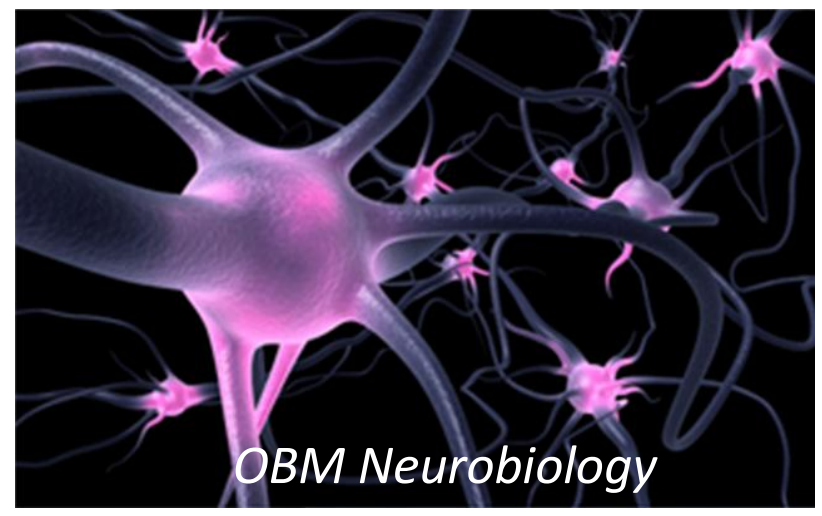

Enjoy OBM Neurobiology by:

1. Submitting a manuscript

2. Joining volunteer reviewer bank

3. Joining Editorial Board

4. Guest editing a special issue

For more details, please visit:

http://www.lidsen.com/journals/neurobiology 